\title{
Changing the glucose cut-off values that define hypoglycaemia has a major effect on reported frequencies of hypoglycaemia
}

\author{
S. G. H. A. Swinnen - P. Mullins - M. Miller • \\ J. B. L. Hoekstra • F. Holleman
}

Received: 26 May 2008 / Accepted: 7 August 2008 / Published online: 20 September 2008

(C) The Author(s) 2008. This article is published with open access at Springerlink.com

\begin{abstract}
Aims/hypothesis The aim of this analysis was to quantify the relationship between the frequency of hypoglycaemia and various glucose cut-off points for the definition of hypoglycaemia, within a range of $\mathrm{HbA}_{1 \mathrm{c}}$ strata.

Methods Data from two trials examining insulin glargine dose titration in 12,837 type 2 diabetic participants starting insulin therapy were combined. Curves for hypoglycaemia frequency plotted against endpoint $\mathrm{HbA}_{1 \mathrm{c}}$ level were constructed, using a range of glucose cut-off points for hypoglycaemia.

Results During the 12-week study period, 3,912 patients recorded 21,592 hypoglycaemic episodes, comprising 242 severe, 8,871 symptomatic and 12,479 asymptomatic events, corresponding to hypoglycaemia event rates of $0.10,3.8$ and 5.3 events per patient year. Increasing the hypoglycaemia cutoff point from, for instance, $<3.1$ to $<3.9 \mathrm{mmol} / 1$ more than doubled the percentage of affected patients, e.g. from 17.7 to $43.3 \%$ at $\mathrm{HbA}_{1 \mathrm{c}} 7.0-7.2 \%$. At higher hypoglycaemia cut-off points the proportion of patients having only asymptomatic hypoglycaemia increased, e.g. from $30.7 \%$ at $<3.1 \mathrm{mmol} / 1$ to
\end{abstract}

Electronic supplementary material The online version of this article (doi:10.1007/s00125-008-1147-0) contains supplementary material, which is available to authorised users.

S. G. H. A. Swinnen $(\bowtie) \cdot J$. B. L. Hoekstra $\cdot$ F. Holleman Department of Internal Medicine, Academic Medical Centre,

Meibergdreef 9, Room F4-257,

1105 AZ Amsterdam, the Netherlands

e-mail: s.g.swinnen@amc.uva.nl

P. Mullins

Department of Statistics, University of Auckland,

Auckland, New Zealand

M. Miller

Department of Biostatistics, Sanofi Aventis,

Bridgewater, NJ, USA
$61.7 \%$ of patients at a cut-off point of $<3.9 \mathrm{mmol} / \mathrm{l}$. In sensitivity analysis, 121 of 1,756 patients with at least one self-monitored blood glucose value $<3.1 \mathrm{mmol} / 1$ experienced severe hypoglycaemia, compared with 149 of 3,912 patients with a self-monitored blood glucose level of $<3.9 \mathrm{mmol} / \mathrm{l}$. Thus, to identify 28 more patients with severe hypoglycaemia, the number of patients experiencing only non-severe hypoglycaemia more than doubled.

Conclusions/interpretation The glucose cut-off point defining hypoglycaemia greatly affects the reported frequency of hypoglycaemia. When hypoglycaemia is to be defined by a predetermined glucose level, to have clinical relevance the cut-off should be set at a lower level than the threshold of $3.9 \mathrm{mmol} / \mathrm{l}$ proposed by the American Diabetes Association.

Keywords Epidemiology · Glucose · Hypoglycaemia · Type 2 diabetes

\section{Abbreviations}

ADA American Diabetes Association

GOAL A1C Glycemic Optimization with Algorithms and Labs at Point of Care A1C

GOT Glycemic Optimization Treatment

SMBG self-monitored blood glucose

\section{Introduction}

Despite its importance, a uniform definition of hypoglycaemia is conspicuously absent when looking at the diabetes literature, particularly when considering randomised controlled trials of glucose-lowering therapies. In 2005 the American Diabetes Association (ADA) sought to remedy this situation by defining hypoglycaemia as an 
event accompanied by a measured plasma glucose concentration $\leq 3.9 \mathrm{mmol} / \mathrm{l}$. This plasma glucose threshold was chosen because in non-diabetic people glucose counter-regulation is activated at this level and antecedent glucose concentrations of $\leq 3.9 \mathrm{mmol} / 1$ reduce counter-regulatory responses to subsequent hypoglycaemia [1].

Obviously, standardised reporting of hypoglycaemia is desirable, but it has been argued that defining hypoglycaemia as any glucose value below $4.0 \mathrm{mmol} / \mathrm{l}$ may lead to overestimation of the frequency of (clinically significant) hypoglycaemia [2]. Plasma glucose falls below this level in health and exposure to glucose levels of $3.5-4.0 \mathrm{mmol} / 1$ is likely to be of little clinical significance [2].

The aim of this analysis was to quantify the relationship between the frequency of hypoglycaemia and various glucose cut-off points for the definition of hypoglycaemia, within a range of $\mathrm{HbA}_{1 \mathrm{c}}$ strata.

\section{Methods}

Included studies Data from two 24-week randomised trials, examining various methods of insulin glargine dose titration in adults with type 2 diabetes uncontrolled by oral glucoselowering agents and requiring insulin therapy, were combined (the Glycemic Optimization with Algorithms and Labs at Point of Care A1C [GOAL A1C] trial [3] and the Glycemic Optimization Treatment [GOT] study [clinicaltrials.gov ID no. NCT00552370]). In both studies insulin glargine was administered once daily at bedtime and titrated weekly, based on fasting self-monitored blood glucose (SMBG) concentrations, measured once daily. Participants were informed about the general symptoms of hypoglycaemia (sweating, drowsiness, etc.) and were instructed to also measure their blood glucose any time they experienced such symptoms. $\mathrm{HbA}_{1 \mathrm{c}}$ was measured by central laboratory analysis (aligned with the Diabetes Control and Complications Trial) every 6 weeks. Hypoglycaemia was defined as an SMBG level $<3.9 \mathrm{mmol} / \mathrm{l}$. If participants indicated that they had experienced symptoms typical of hypoglycaemia the event was classified as symptomatic. Hypoglycaemic events were classified as severe if the patient required assistance and (1) there was prompt response to treatment, or (2) the SMBG level was $<2.0 \mathrm{mmol} / \mathrm{l}$.

Method To minimise the destabilising effects associated with treatment intensification, the analysis period was defined as the final 12 weeks of the included trials. Study participants without an endpoint $\mathrm{HbA}_{1 \mathrm{c}}$ measurement (week 24, or last observation carried forward obtained after week 12) were excluded $(n=2,778)$. $\mathrm{HbA}_{1 \mathrm{c}}$ was categorised using an arbitrary category width of $0.3 \%$ and $\mathrm{HbA}_{1 \mathrm{c}}$ categories $\leq 5.1 \%$ and $>11.7 \%$ were excluded because of limited patient numbers $(n=93)$.
The analysis was based on all daily fasting glucose measurements and any additional measurements with an SMBG concentration $<3.9 \mathrm{mmol} / \mathrm{l}$, i.e. all symptomatic and asymptomatic hypoglycaemic episodes with blood glucose below this level were included. Severe hypoglycaemic episodes were analysed separately. Hypoglycaemia frequency was plotted against endpoint $\mathrm{HbA}_{1 \mathrm{c}}$ category using a range of predefined glucose cut-off points for hypoglycaemia. Both the proportions of patients experiencing at least one episode of hypoglycaemia and hypoglycaemia event rates were examined. A sensitivity analysis was performed to compare the sensitivity and specificity of a range of hypoglycaemia cut-off points for identifying patients experiencing severe hypoglycaemia.

\section{Results}

The analysis population consisted of 9,966 patients, with mean age 56.4 years, BMI $34.5 \mathrm{~kg} / \mathrm{m}^{2}$, diabetes duration 8.5 years and baseline $\mathrm{HbA}_{1 \mathrm{c}} 9.0 \%$ (see Electronic supplementary material [ESM] Table 1). Of these participants, 3,912 had 21,592 SMBG confirmed hypoglycaemic episodes, including 242 severe events. Of the 21,350 non-severe hypoglycaemic episodes, 8,871 (41.6\%) were symptomatic and 12,479 (58.4\%) asymptomatic. Hypoglycaemia event rates were $3.8,5.3$ and 0.10 events per patient year for symptomatic, asymptomatic and severe hypoglycaemia respectively.

Figure 1 shows that, compared with a lower hypoglycaemia cut-off point, such as $<3.1 \mathrm{mmol} / \mathrm{l}$, the ADA definition of $3.9 \mathrm{mmol} / \mathrm{l}$ more than doubled the percentage of affected patients across a wide range of $\mathrm{HbA}_{1 \mathrm{c}}$ strata, e.g. from 17.7 to $43.3 \%$ at $\mathrm{HbA}_{1 \mathrm{c}}$ of about $7 \%$. Considering event rates, the discrepancy was even larger, with 0.3 vs 1.3 events per 100 patient days, as the number of events per patient also increased with higher cut-offs (ESM Fig. 1). At higher hypoglycaemia cut-off points the proportion of patients having only asymptomatic hypoglycaemia, i.e. without any symptomatic events, increased from (for instance) $30.7 \%$ at a cut-off of $<3.1 \mathrm{mmol} / 1$ to $61.7 \%$ at a cut-off of $<3.9 \mathrm{mmol} / \mathrm{l}$ (Fig. 2).

Of all patients, $1.5 \%(n=149)$ recorded a severe hypoglycaemic episode. This percentage of affected patients was consistent across $\mathrm{HbA}_{1 \mathrm{c}}$ strata up to an $\mathrm{HbA}_{1 \mathrm{c}}$ level of $9.9 \%$, above which no participant experienced severe hypoglycaemia. In sensitivity analysis, again taking the $3.1 \mathrm{mmol} / 1$ cut-off point as an example, 121 of 1,756 patients with at least one SMBG $<3.1 \mathrm{mmol} / 1$ (i.e. including all non-severe and severe hypoglycaemic events with SMBG $<3.1 \mathrm{mmol} / \mathrm{l}$ ) experienced severe hypoglycaemia, compared with 149 of 3,912 patients with at least one 
Fig. 1 Proportion of patients experiencing at least one nonsevere hypoglycaemic episode during the 12-week analysis period for a range of predefined glucose cut-off points for the definition of hypoglycaemia, plotted against endpoint $\mathrm{HbA}_{1 \mathrm{c}}$ categories
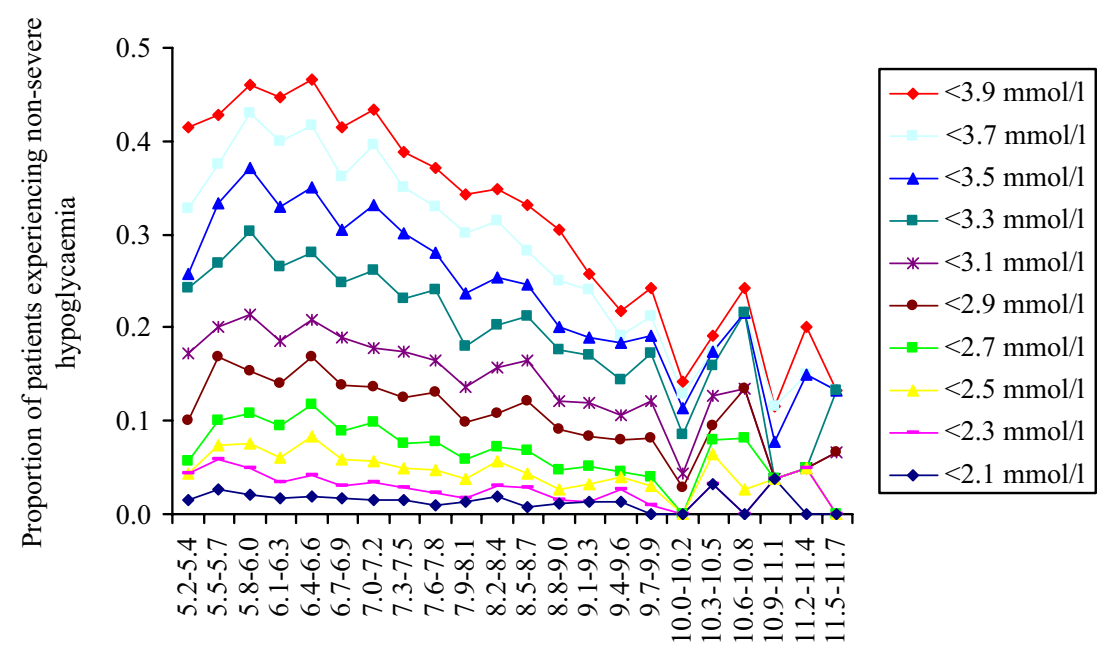

Endpoint $\mathrm{HbA}_{1 \mathrm{c}}(\%)$
SMBG $<3.9 \mathrm{mmol} / \mathrm{l}$. Thus, to identify 28 more patients with severe hypoglycaemia, the number of patients experiencing only non-severe hypoglycaemia more than doubled. Similarly, $82.2 \%(199 / 242)$ of the severe hypoglycaemic episodes occurred in patients who had had a SMBG $<3.1 \mathrm{mmol} / \mathrm{l}$ at some other time during the 12 weeks, and $97.5 \%$ (236/242) in patients who had had a SMBG $<3.7 \mathrm{mmol} / 1$.

\section{Discussion}

Our main finding was that, in a large cohort of type 2 diabetic patients starting insulin therapy, higher cut-off points for the definition of hypoglycaemia considerably increased the reported frequency of hypoglycaemia, and particularly that of asymptomatic hypoglycaemia. Higher cut-offs identified more patients having severe hypoglycaemia, but this was at the expense of the specificity, i.e. a very large number of patients that did not experience severe hypoglycaemic episodes were also labelled as 'at risk'.

Because we combined the data of two large clinical trials, our analysis was based on a substantial number of hypoglycaemic episodes that had been systematically recorded. Nevertheless, hypoglycaemia may have been under-reported as in both trials investigators depended on the patients bringing their diaries to the site visits. Moreover, hypoglycaemia had been defined as an event confirmed by an SMBG value $<3.9 \mathrm{mmol} / \mathrm{l}$, so we did not include episodes with symptoms typical of hypoglycaemia but without glucose determinations. Third, as the study population had only just started insulin and thus many were hypoglycaemia-naive, some hypoglycaemic episodes may not have been recognised as such. However, this under-recognition was minimised by repeated discussion of hypoglycaemia symptomatology during the clinic visits. Finally, the presence of hypoglycaemia unawareness, which was not formally assessed, could have confounded our results because this is associated with an increased frequency of (severe) hypoglycaemia but fewer selfreported events $[4,5]$. However, hypoglycaemia unawareness is rare in patients with type 2 diabetes recently initiated on basal insulin therapy.

The proportions of affected patients and hypoglycaemia event rates we found were higher than those reported for newly diagnosed participants in the UK Prospective Diabetes Study [6], but equal to those reported for type 2 diabetic patients newly started on insulin $(<2$ years $)$ in a recent observational study [7]. With regard to severe hypoglycaemia, population-based and retrospective studies of insulintreated individuals with type 2 diabetes reported higher event rates [8-10]. However, our study population had just started insulin, and the frequency of hypoglycaemia and the prevalence of hypoglycaemia unawareness are much greater in people with type 1 diabetes and type 2 diabetic patients with a longer duration of insulin treatment. It might be useful to perform an analysis such as ours for these patient groups

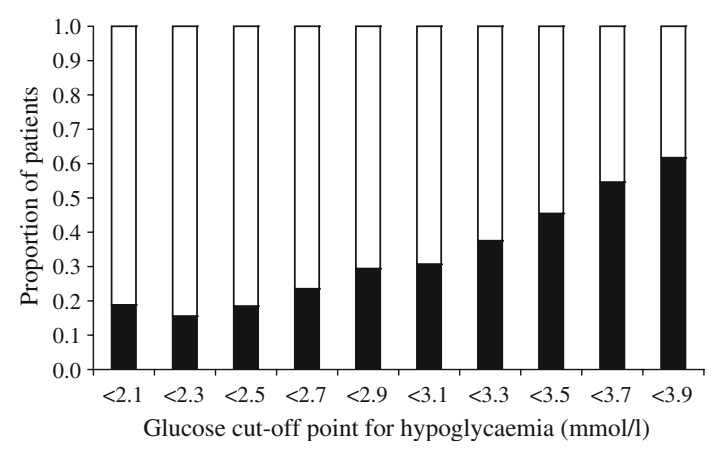

Fig. 2 Proportion of patients experiencing only asymptomatic nonsevere hypoglycaemic episodes during the 12-week analysis period (black bars) vs proportion of patients also experiencing symptomatic hypoglycaemic episodes (white bars), for a range of predefined glucose cut-off points for the definition of hypoglycaemia 
as well. Although it may prove necessary to use different glucose cut-off points defining hypoglycaemia for different patient populations, we expect that the demonstrated impact of the hypoglycaemia cut-off on the reported frequencies of hypoglycaemia can be largely generalised to other patient groups.

According to our analysis, more than $40 \%$ of type 2 diabetic patients starting insulin therapy experienced hypoglycaemia when the ADA definition was used. These events were usually asymptomatic and of limited use in identifying patients at risk of severe hypoglycaemia. Since the clinical significance of exposure to glucose concentrations of $3.5-4.0 \mathrm{mmol} / \mathrm{l}$ is probably minor, and as strict avoidance of such glucose levels is likely to have an adverse effect on average glycaemia, we propose a hypoglycaemia definition that is lower than the cut-off point of $3.9 \mathrm{mmol} / \mathrm{l}$, particularly in individuals with type 2 diabetes who have just started insulin treatment.

Acknowledgements This study was supported financially by sanofi aventis.

Duality of interest S. G. H. A. Swinnen is employed by the Department of Internal Medicine of the Academic Medical Centre, Amsterdam, the Netherlands, partly through funding from Novo Nordisk and sanofi aventis for the conduct of clinical trials. P. Mullins has received research support from sanofi aventis. M. Miller is employed as Senior Manager Statistics at sanofi aventis. J. B. L. Hoekstra has received honoraria for consultancy work from Novartis and sanofi aventis. F. Holleman is currently principal investigator for a multinational trial sponsored by sanofi aventis, has served on advisory boards for sanofi aventis and received a study grant from Novo Nordisk.

Open Access This article is distributed under the terms of the Creative Commons Attribution Noncommercial License which permits any noncommercial use, distribution, and reproduction in any medium, provided the original author(s) and source are credited.

\section{References}

1. American Diabetes Association Workgroup on Hypoglycemia (2005) Defining and reporting hypoglycemia in diabetes: a report from the American Diabetes Association Workgroup on Hypoglycemia. Diabetes Care 28:1245-1249

2. Amiel SA, Dixon T, Mann R, Jameson K (2008) Hypoglycaemia in type 2 diabetes. Diabet Med 25:245-254

3. Kennedy L, Herman WH, Strange P, Harris A, for the GOAL A1C Team (2006) Impact of active versus usual algorithmic titration of basal insulin and point-of-care versus laboratory measurement of $\mathrm{HbA}_{1 \mathrm{c}}$ on glycemic control in patients with type 2 diabetes: The Glycemic Optimization with Algorithms and Labs at Point of Care (GOAL A1C) trial. Diabetes Care 29:1-8

4. Gold AE, MacLeod KM, Frier BM (1994) Frequency of severe hypoglycemia in patients with type I diabetes with impaired awareness of hypoglycemia. Diabetes Care 17:697-703

5. Kubiak T, Hermanns N, Schreckling HJ, Kulzer B, Haak T (2004) Assessment of hypoglycaemia awareness using continuous glucose monitoring. Diabet Med 21:487-490

6. UK Prospective Diabetes Study (UKPDS) Group (1998) Intensive blood-glucose control with sulphonylureas or insulin compared with conventional treatment and risk of complications in patients with type 2 diabetes (UKPDS 33). Lancet 352:837-853

7. UK Hypoglycaemia Study Group (2007) Risk of hypoglycaemia in types 1 and 2 diabetes: effects of treatment modalities and their duration. Diabetologia 50:1140-1114

8. Donnelly LA, Morris AD, Frier BM et al (2005) Frequency and predictors of hypoglycaemia in type 1 and insulin-treated type 2 diabetes: a population-based study. Diabet Med 22:749-755

9. MacLeod KM, Hepburn DA, Frier BM (1993) Frequency and morbidity of severe hypoglycaemia in insulin-treated diabetic patients. Diabet Med 10:238-245

10. Henderson JN, Allen KV, Deary IJ, Frier BM (2003) Hypoglycaemia in insulin-treated type 2 diabetes: frequency, symptoms and impaired awareness. Diabet Med 20:1016-1021 